\title{
Bicortical Screw and Needle Welded Together as Effective Implant Technique for Immediate Load of SINGLE Tooth in Aesthetic Zone Characterized by Severe Bony Reabsorption: Cases Report
}

\author{
Luca Dal Carlo, Marco E. Pasqualini, and Franco Rossi
}

\section{ABSTRACT}

After a long period of time in which submerged implants were used just with delayed load, scientific evidence has led to immediate loading, finally re-evaluating the long lasting experience gotten with one-piece implants.

In aesthetic area, if bone is deep and wide, immediate load can be performed with any type of implants, with scarce risk of failure.

Situations in which bone is scarce are frequent and impose to choose between performing a suitable technique compatible with immediate loading or renouncing to immediate loading.

In our experience, implant technique based on the welding-in-mouth of a titanium needle to main implant is regularly destined to success, because the needle implant, deeply anchored to bone, compensates the lateral forces that normally push the tooth forward.

The long lasting experience accrued since over 30 years in our professional offices leads us to suggest this technique as a standard solution while dealing with bone reabsorption in the aesthetic area. We are certain that further studies will confirm our conclusions.

Keywords: Immediate implant, Aesthetic area, composed single implant, Welding machine.
Submitted : May 03, 2021

Published : May 24, 2021

ISSN: 2593-8339

DOI: 10.24018 /ejmed.2021.3.3.857

\section{Luca Dal Carlo*}

President of New Italian Implants Study Group, Venice, Italy.

A.A.I.P. Master.

(e-mail: lucadalcarlo@gmail.com)

Marco E. Pasqualini

Scientific Director of New Italian Implants Study Group. A.A.I.P, Master. Private practice in Milan, Italy.

(e-mail: dott.marcopasqualini@ gmail.com)

Franco Rossi

A.I.S.I. Deputy Vice President.

Private practice in Varese, Italy. (e-mail: francorossi020@ gmail.com)

*Corresponding Author

\section{INTRODUCTION}

The occurrence of periodontal disease and bone reabsorption around a tooth of the aesthetic zone is often accompanied by lack of alveolus surrounding cortex walls and, therefore, immediately loaded root-form implants are contra-indicated. As a matter of fact, in such conditions, risk of failure is high, also taking into consideration the fact that superior incisors are pushed forward by inferior ones. Bony augmentation is a slow speed technique, useful to restore volume, but useless, in the first phase, to bear lateral load effort. In addition, acceptance of grafted bone depends on numerous factors, including reactivity of the residual natural bone in which lied the affected natural tooth. This acceptance is often unpredictable. Due to these assessments, bone graft is normally followed by 4-6 months of wait before loading [1], [2].

When immediately loading the implant, success is entrusted on residual native bone.

\section{TALKING WITH THE PATIENT}

Former considerations are related to patient's requests, which can exclude therapy. As a matter of fact, if we understand that satisfying patient wills will increase failure risks, we must give up. This situation is not so rare. Many times, patient is bearing diseased teeth, which have damaged supporting bone and he/she wants immediate fix tooth with same or increased volume. It is therefore important to understand the causes of previous tooth failure, being aware that an implant, especially early after intervention, must be gently handled. Detecting occlusal dynamics which could jeopardize implant stability is a key factor for success (Fig. 6) [3], [4].

To apply immediate loading after extraction in situations in which bone is reabsorbed, it is necessary to use an implant technique capable to provide immediate stability of the little implant part anchored to bone. We cannot use a standard technique, but, on the contrary, an implant technique based on anatomic residual recesses and human skill. 


\section{The StABILIZED SCREW TeChNiQUE}

If immediately loaded, a single screw inserted in scarce bone in the anterior superior maxilla can go to failure due to minimum trauma or incongruous function. Numerous studies have demonstrated that, in majority of cases, buccal bone thickness is less than $1 \mathrm{~mm}$ [5]. If, in addition, bone depth is poor, such therapy is a gamble easy to lose.

A technique which combines immediate loading with high rate of success is then needed.

If patient request is immediate loading, we can take into consideration the classical implant technique based on the welding-in-mouth of a needle implant (secondary implant) firmly anchored to the deep cortex to the screw (main implant). This proceeding provides, since the beginning, a stable single unit titanium structure. This technique was introduced to implant practice during the early 80ies [6]-[8]. This technique is resolving not only the bone reabsorption problem in height, but the frequent situation of lack of parallelism, too. As a matter of fact, bone deficit leads to insert main implant on one side and not in the ideal position (Fig. 1, a). By exploiting bone located deeply in the medial posterior pre-maxilla, the needle implant provides immediate stability to main implant, to which it has been welded immediately after extraction. As a matter of fact, titanium needle can be deeply inserted reaching the bony cortex of the nose, behind the alveolar process of pre-maxilla, with the additional effect of increasing crown root ratio. During the first post-intervention period, the implant which is guaranteeing stability is the secondary one (Fig. 1, b). We can then plan a project which allows the patient to be immediately restored by means of a fixed provisional prosthesis.

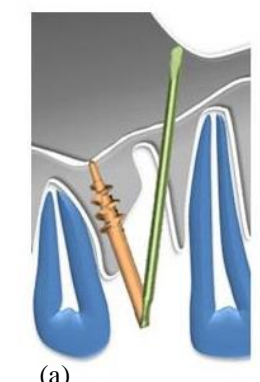

(a)

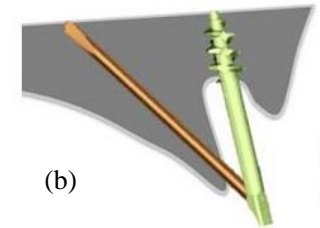

Fig. 1. (a) The screw implant exploits the residual bone in one side, while the needle implant reaches the nose cortex posteriorly, increasing crown-root ratio. (b) In a sagittal view, it is easy to understand the ratio of this technique. (c) Same concept is applied to stabilize weakly rooted trees protecting them from the lateral force of the wind, till the roots grow, reaching enough depth.

\section{TREATMENT PlanNING}

Decision of adding a welded implant must be taken before the beginning of the intervention, so as to manage available spaces for the best. First hole must be the one for the main implant. After its positioning, a thin bur, 1,0 mm. wide (Maillefer torpans fit good), is used to perform a little hole in the cortex of the alveolus, with posterior direction. Needle titanium implant is then inserted, progressing with slow rotation, and checking its final bicortical position by gentle hammering. After an X-ray control, the two implants are welded in mouth (Fig. 4 and 11). A provisional crown in adapted with resin and the occlusal functions are checked. The crown is then cemented, and the patient can go home with his new tooth in mouth.

The provisional prosthesis must be cautious, taking care of eliminating all the risks of displacing forces (Fig. 8, d). This precaution is mandatory, because, during the first period after intervention, stable implant-bone interface is lacking. After osteo-inclusion implant will be capable to bear stronger forces, which, anyway, must be well managed.

\section{Clinical CASE 1}

Patient BF, male, aged 48. Being edentulous in the left posterior sectors, patient had been previously treated with implants in the left superior and inferior sector (Fig. 2). After left side treatment completion, resolving fractured 1.2 was necessary. In this kind of cases, it is immediately comprehensible that the buccal wall of the bone is completely lacking, irreversibly damaged by inflammation and incongruous occlusal forces. Occlusal trauma during clenching and protrusion was confirmed by simply observing the tooth moving during these cited functions (Fig. 3, a). Patient rejected any removable prosthetic solution and requested immediate fixed prosthetic crown.

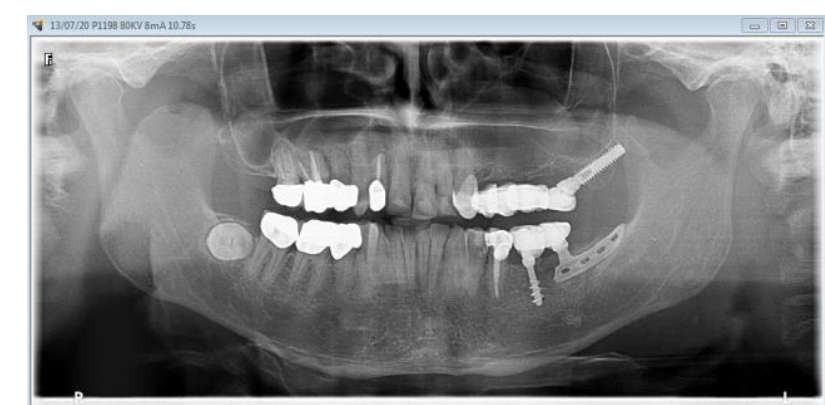

Fig. 2. Pre-Operatory OPG

Treatment planning was conceived and illustrated to the patient (Fig. 3, c). Scarceness of bone imposed the use of implants capable to exploit the poor residual bone. Bicortical screw implant stabilized by means of bicortical needle implant was then selected as the solution provided by the best immediate stability. Intervention was described, including the need of weld immediately the two implants together in patient mouth. Immediate temporary prosthetic crown was then discussed, explaining the need of slightly modifying the antagonist teeth so as to minimize the risk of traumas to the provisional tooth. It must be underlined that, any cause of tooth failure, the lack of buccal bone deprives the implant of the means with whom anterior forces are counterbalanced.

\section{A. Intervention}

Immediately post-extractive implant was planned. Local anesthesia with adrenalin 1/100.000 was performed in both buccal and palatal sides. After having reached effective block, extraction of the tooth was performed (Fig. 3, b). 


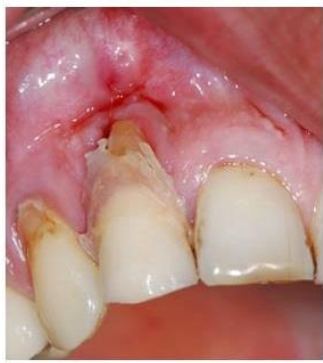

(a)

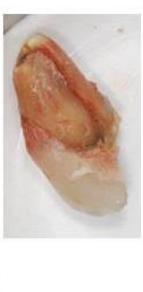

(b)

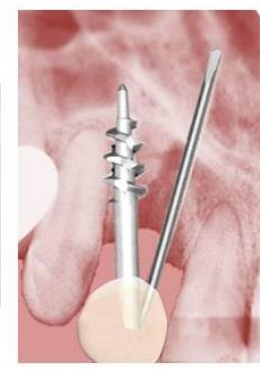

(c)
Fig. 3. (a) The endangered and unstable situation of the 1.2. (b) Tooth after extraction. Fracture line of the root bearing the prosthetic crown. (c) Rehabilitation plan.

Careful toilette of the socket by means of hand instruments was performed.

A one-piece screw implant was inserted inside the triangle of bone which lied between the sockets of the canine and the lateral incisor, while a needle implant was inserted posteriorly. Both implants reached the deep cortical bone, which is widely indicated as one of the mains stabilization requisites [9]-[12]. The two implants were welded-in-mouth by means of intra-oral-welding machine [13], [14]. Immediate provisional prosthesis was cemented, taking care about possible causes of trauma which could jeopardize implant stability. After 4 months, final prosthesis was performed, fulfilling the two goals of functional and aesthetic restoration (Fig. 5).

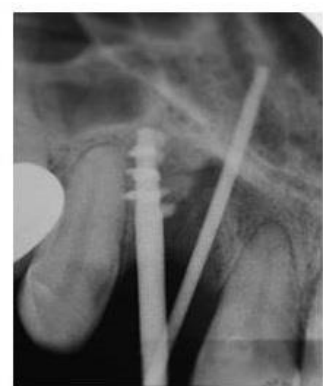

(a)

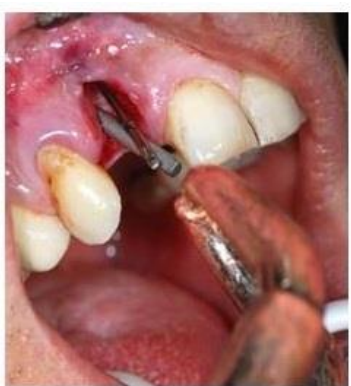

(b)
Fig. 4. (a) Screw and needle inserted in the scarce remaining bone, reaching deep cortex (bicorticalism). Screw tip has been eliminated to increase penetration of implant part provided by coils. (b) The two titanium implants have been welded in mouth by means of the Mondani intra-oral welder. Abutment was milled and temporary crown was immediately cemented.
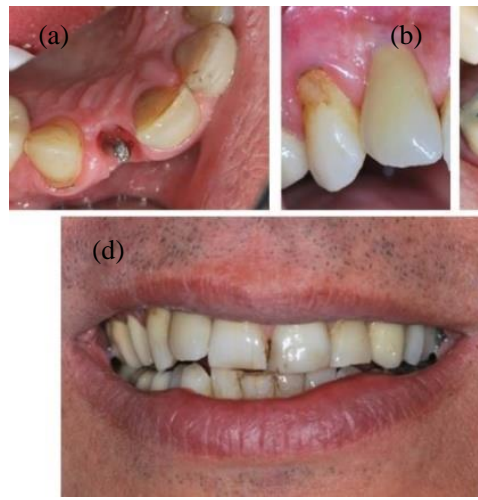

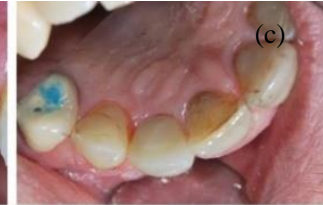

(e)

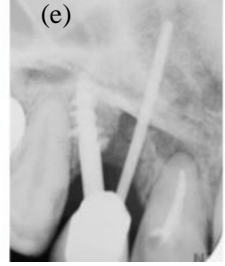

Fig. 5. (a)-(c). At the moment of final prosthesis cementation, implant is stable, gums are healthy and $3 \mathrm{~mm}$. of soft tissues depth had been recovered. (d) Aesthetics of the new crown fits to patient physiognomy. (e) X-ray taken immediately after definitive crown cementation. Despite immediate loading, no bone reabsorption has been happening around the two implants, which are firmly anchored to bone.

\section{Clinical CASE 2}

Patient TP, age 55, male. Left incisor naturally expelled by occlusal trauma. Severe bone reabsorption (Fig. 6). Treatment by means of stabilized screw immediately loaded by means of provisional prosthesis.

Definitive crown surrounded by good-looking healed tissues, despite immediate loading (Fig. 7).
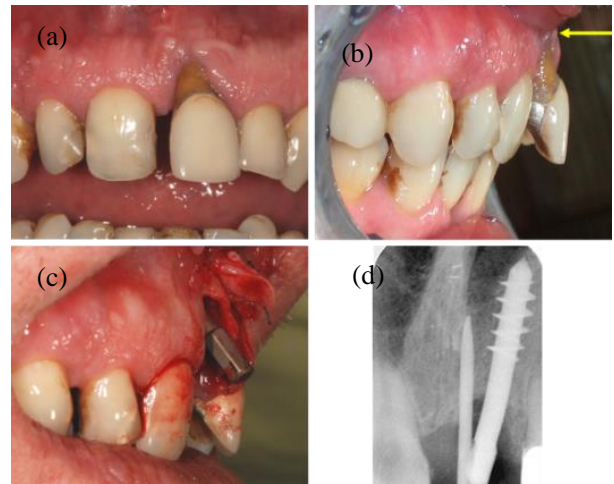

Fig. 6. (a), (b) Naturally expelled tooth, moving under inferior incisor pressure. (c), (d) Screw stabilized by welded titanium needle inserted. Implants reaching the deep cortical bone.

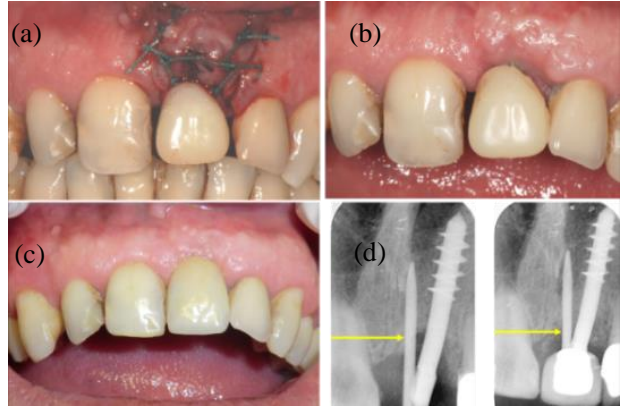

Fig. 7. (a), (b) Immediate loading and 10 days control

(c), (d) Definitive prosthesis. X-rays testifying bone healing and maintenance.

\section{Clinical CASE 3}

Patient RG, age 60, female. Fractured 2.3 root bearing crown with customized post since long time. Vestibular fistula testifies buccal bone loss. Bicortical screw and needle were inserted immediately after extraction and adequate surgical toilette. Implants were immediately welded in mouth [13]. Provisional prosthesis was cemented at end of intervention, taking care of avoiding displacing forces. After bone regeneration, definitive crown was built, recovering physiologic function (canine guidance) (Fig. 8).
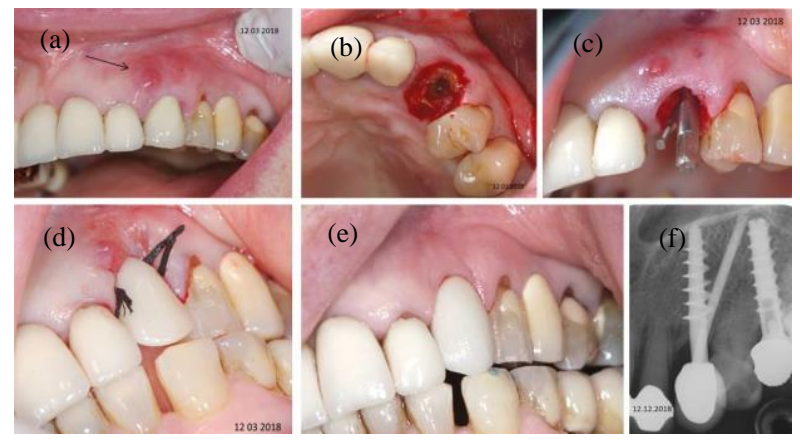

Fig. 8. (a)-(c) Clinical view of the fistula and fractured root of tooth 2.3 after crown and post disassembling. Screw a needle inserted inside tooth alveolus, reaching deep cortex. (d) Provisional prosthesis. (e-f) Definitive prosthesis and X-ray control. 


\section{Clinical Case 4}

Patient CG, age 52, female. Severe periodontal disease around 1.3, irreversibly damaged. Tooth extraction, provisional single crown out of function and subsequent definitive one. Definitive crown provides canine guidance (Fig. 9, 10).
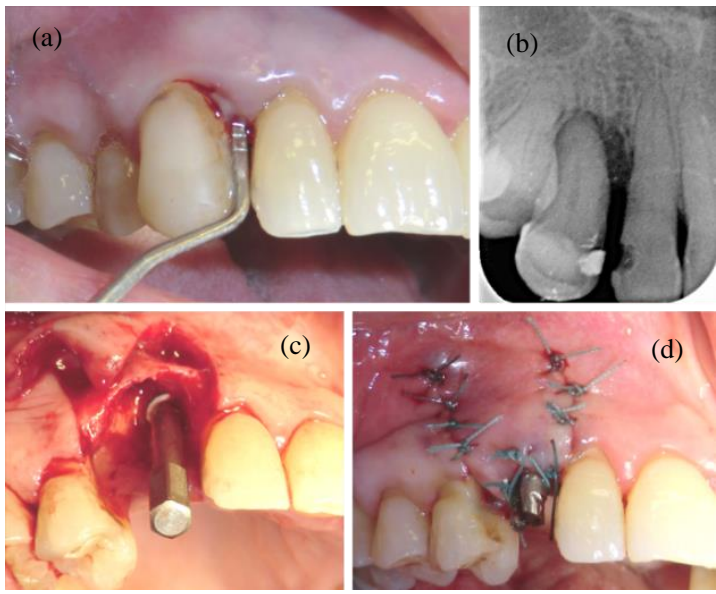

Fig. 9. (a), (b) Periodontal probing and X-ray confirm necessity of 1.3 tooth extraction. (c), (d) Severe bone reabsorption. Screw and needle inserted.
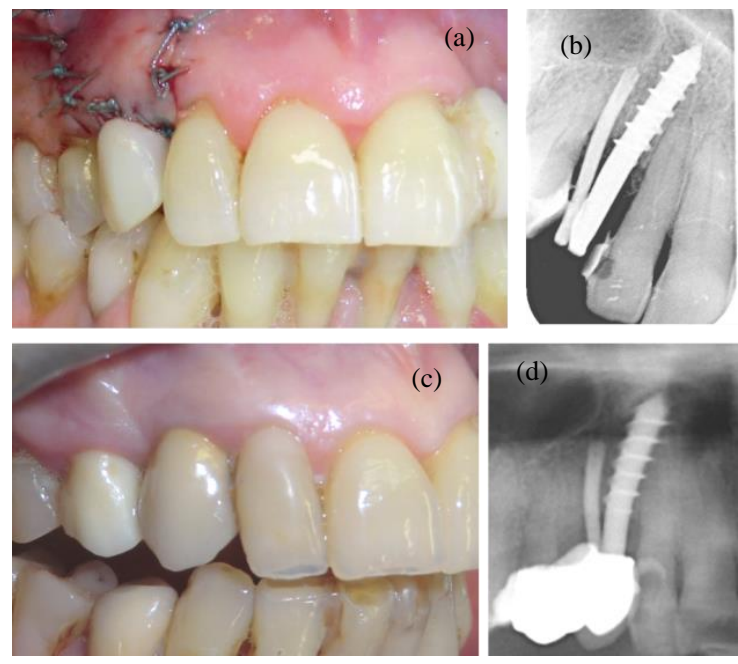

Fig. 10. (a), (b) Provisional prosthesis free of occlusal contacts. X-ray taken at intervention end. (c), (d) Definitive crown bearing canine guidance. X-ray control after 8 years.

\section{Clinical Case 5}

Patient FS, age 74, Female. Aching and moving superior central incisor, with horizontal tooth fracture. In this clinical case, same natural crown was used as provisional prosthesis [15], [16]. Patient then decided to hold on as definitive one. To recover same tooth position, the Jig Replace technique was used [15], i.e., adapting some resin or impression material to tooth and adjacent ones to repeat same tooth position. Tooth was removed, root scooped out to allow adaptation on implants. After careful surgical toilette, screw and needle were inserted immediately welded in mouth, and milled as prosthetic abutment. Natural crown was adapted with resin and cemented (Fig. 11).

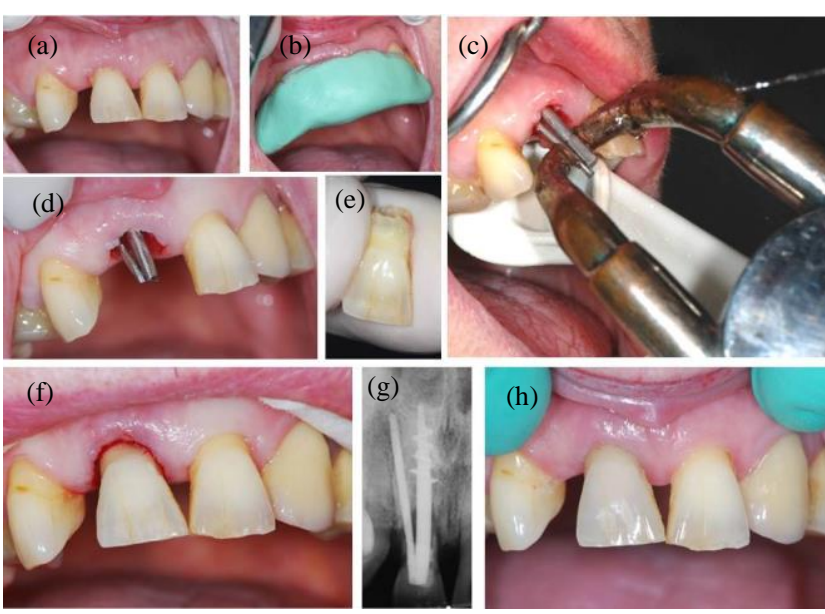

Fig. 11. (a) Irreversibly damaged 1.1 tooth. (b) Jig of impression material. (c) Intra-oral welding of the bicortical screw and needle.

(d) Milled abutment and emptied natural crown. (f) Crown cemented at end of session, in same position of the beginning, beared by new root. (g) X-ray. (h) Control

\section{REFERENCES}

[1] Wang X, Zhang T, Yang E, Gong Z, Shen H, Wu H, Zhang D Biomechanical Analysis of Grafted and Nongrafted Maxillary Sinus Augmentation in the Atrophic Posterior Maxilla with ThreeDimensional Finite Element Method. Scanning. 2020 Oct 2;2020:8419319. PMID: 33093935.

[2] Alagl AS, Madi M. Localized ridge augmentation in the anterior maxilla using titanium mesh, an alloplast, and a nano-bone graft: a case report. Journal of International Medical Research 2018, Vol. 46(5) 2001-2007. PMID: 29529906

[3] Pasqualini U, Pasqualini ME. Treatise of Implant Dentistry. 2009 Ariesdue Carimate (CO). PMID: 28125196.

[4] Hsu YT, Fu JH, Al-Hezaimi K, Wang HL. Biomechanical Implant Treatment Complications: A Systematic Review of Clinical Studies of Implants with at Least 1 Year of Functional Loading. International Journal of Oral \& Maxillofacial Implants. 2012, Vol. 27 Issue 4, p894904. PMID: 22848892

[5] Braut V, Bornstein MM, Belser U, Buser D. Thickness of the anterior maxillary facial bone wall-a retrospective radiographic study using cone beam computed tomography. Int $\mathrm{J}$ Periodontics Restorat Dent 2011; 31(2): 125-31. PMID: 21491011.

[6] Apolloni M: Atlante pratico di implantologia dentale. 1989 Edi Ermes Ed. Milano.

[7] Pasqualini ME, Mangini F, Colombo A, Manenti PA, Rossi F. Stabilizzazione di impianti emergenti a carico immediato. Saldatrice endorale. Dental Cadmos 2001;9:67.

[8] Pasqualini M, Rossi F, Carlo LD, Comola G. Rehabilitations of a single element with one-piece implants with electrowelded needles: A different approach. Dent Res J (Isfahan). 2018 Nov-Dec;15(6):447452. PMID: 30534174

[9] Garbaccio D.: The Garbaccio bicortical self-threading screw. Riv Odontostomatol Implantoprotesi. Jan-Feb 1983;(1):53-6. PMID: 6350959.

[10] Rossi F, Pasqualini Me, Dal Carlo L, Shulman M, Nardone M, et al (2015) Immediate loading of maxillary one-piece screw implants utilizing intraoral welding: a case report. J Oral Implantol 41(4): 473 475. PMID: 25647017

[11] Wang K, Li DH, Zhou JX, Zhang CJ, Liu BL, Li YL. Influence of bicortical anchorage on the natural frequencies of dental implant. Hua Xi Kou Qiang Yi Xue Za Zhi. 2006 Feb;24(1):86-8. Chinese. PMID: 16541668.

[12] Thomé G, Caldas W, Bernardes SR, Cartelli CA, Gracher AHP, Trojan LC. Implant and prosthesis survival rates of full-arch immediate prostheses supported by implants with and without bicortical anchorage: Up to 2 years of follow-up retrospective study. Clin Oral Implants Res. 2020 Nov 19. PMID: 33211323.

[13] Mondani P.L., Mondani P.M.: The Pierluigi Mondani intraoral electric solder. Principles of development and explanation of the solder using syncrystallization. - Riv Odontostomatol Implantoprotesi. 1982 JulAug;(4):28-32. PMID: 6130503

[14] Dal Carlo L, Pasqualini Me, Mondani Pm, Rossi F, Moglioni E, Shulman M: Mondani intraoral welding: historical process and main 
practical applications. J of Biol Regulators \& Homeostatic Agents 2017; Vol. 31, no. 2 (S1). PMID: 28691478.

[15] Dal Carlo L.: Jig - Replace - Novoie V Stomatologii, Moskow, 4/160/2009:36-41.

[16] Dal Carlo L., Dal Carlo Z.: Elementi di Selezione degli impianti endoossei. 2020 Edizioni Accademiche Italiane, Chap. 15:182-189.

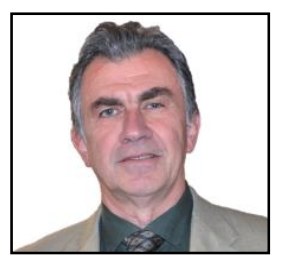

Dr. Luca Dal Carlo was born in Venice, Italy, on October the $16^{\text {th }}, 1962$. He was graduated in Odontology and Prosthetic Dentistry at the Padua University on March $29^{\text {th }}$, 1988. Since that time, he holds a private practice in center Venice, Italy. Over 30 years experienced in multi-modal implant dentistry, intra-oral welding, immediate loading and related prosthetics.

Author of numerous courses and lectures about implant and prosthetic dentistry.

Lecturer for 5 consecutive years at the annual meeting of the "Odontology Professors Board" in Rome, Italy.

One of the authors of the Odontology Dentistry Recommendations of the Italian Ministry of Health, 2014 and 2017 editions.

Author of 100 scientific articles about the topic of implant dentistry, whose contents have been incorporated in his text book "Elementi di Selezione degli Impianti Endoossei” 2020, Edizioni Accademiche Italiane. Several textbooks from Specialists of Implant Dentistry host chapters from him.

Author of a 25 years statistical study over 7000 implants, with 5, 8, 10 years gate controls.

President of the New Italian Implants Study Group (NuovoGISI) since 2009.

Master of the American Academy of Implant Prosthodontics (AAIP).

Active Member of the Societad Espanola de Implantes (SEI)

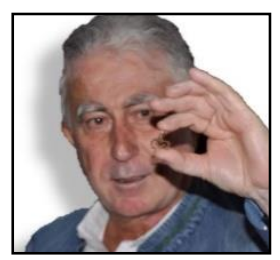

Dr. Marco E. Pasqualini was born in Modena,

Italy, on March 17th, 1952.

He attended the University of Milan, graduating with a degree in medicine, and then earned a postgraduate degree cum laude in dentistry at the University of Modena, Italy.

He was non-tenured professor of clinical maxillofacial prosthetics at the School of Dentistry, which is part of the Department of Medicine at the University of Modena (academic year 1991-1992).

He held a non-tenured position with the Department of Medicine at the University of Bari, Italy, teaching "The role of plate-form implants in oral rehabilitation" as part of the coursework on oral diseases for the undergraduate program in dental hygiene (academic year 2001-2002).

$\mathrm{He}$ was also a non-tenured professor at the Department of Dental Sciences of the School of Medicine at the Gabriele d'Annunzio University of Chieti for the postgraduate course on clinical implantology and biomaterials (academic year 2004-2005) and the theoretical-practical refresher course on electrowelded implantology (academic year 20052006), both of which directed by Stefano Fanali, professor of dentistry).

Author and co-author of 84 articles that have been published in national and international scientific journals, he has a personal photographic archive about dentistry composed of more than 20,000 slides. He worked with his uncle, Prof. Ugo Pasqualini, for 20 years in both daily practice and research work, and shares his scientific principles, outlined in the book "Occlusal pathologies. Pathogenesis and therapy" (Italian).

He was vice president of A.I.S.I. (Italian Academy of Implant Stomatology), and he is a GISI (Italian Implant Study Group) fellow and a charter member of COM (Cenacolo Odontostomatologico Milanese). He was member of the board of directors of GISIGM (Giordano Muratori Italian Implant Study Group), directed by Prof. Francesco Mangini of the University of Bari.

He has been president of the SOMECOI (Società Medico Chirurgica di Odontoiatria Implantoprotesica) since 1999 and is a charter member of AIIP (Academia Internacional de Implantologia y Periodoncia).

He is Master AAIP (American Accademy of Implant Prosthodontics) and active member of ICOI (International Congress of Oral Implantologists) and SEI (Sociedad Española de Implantes).

Author of the "Treatise of Implant Dentistry, The Italian Tribute to the Modern Implantology" (2009) (PubMed indexed).

As national and international lecturer, he has taught postgraduate courses for updates on implantology and occlusions.
Dr. Pasqualini has a private practice in Milan, Italy.as editorial advisor for the scientific journal Doctor Os as well as reviewer for the Journal of Osseointegration,

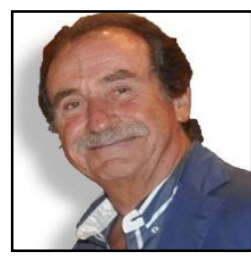

Dr. Franco Rossi was born in Varese, Italy, on November the $9^{\text {th }}, 1944$. Occupational field: Doctor Surgeon Specialist in Dentistry.

Professional Assignment 2013:

Professor in the Master's Degree in Implantology and Dentures Medical School University Catholic "Nostra Signora del Buon Consiglio" - Tirana, Albania

Education and Training:

- 1971 Degree in Medicine and Surgery University of Milano.

- 1974 Specialized in anaesthesia and resuscitation University of Milano.

- 1978 Specialized in Dentistry University of Modena.

- 2009 Contributor to the book "Treatise of Implant Dentistry" of Ugo and Marco E. Pasqualini - Ariesdue Edition.

- 2009 Contributor to the book "Implantoprosthetic Atlas" of Pier Luigi Floris - Cic International Edition.

Further Informations:

- National Deputy Vice President and President of the Scientific Commission AISI (Italian Academy Stomatology Implantoprosthetic).

- Fellow AAIP (American Academy of Implant Prosthodontics).

- Fellow NuovoGISI (New Italian Group Implant Studies).

- Fellow SISOS (Italian Society of Odontostomathologic History).

- Fellow SEI (Societad Espanola De Implantes).

- National and international lecturer.

Author of 76 scientific publications on national and international journals 